\title{
Urinary Methylmalonic Acid in Patients with Acute Myocardial Infarction
}

\author{
Turgay Celik $^{\mathrm{a}}$ Ejder Kardesoglu ${ }^{\mathrm{d}}$ Atila lyisoy ${ }^{\mathrm{a}}$ Omer Ozcan $^{\mathrm{e}}$ Selim Kilic ${ }^{b}$ \\ Halil Yaman ${ }^{c}$ \\ Departments of a Cardiology, ${ }^{b}$ Epidemiology and ${ }^{c}$ Clinical Biochemistry, School of Medicine, \\ Gulhane Military Medical Academy, Etlik-Ankara, and Departments of ${ }^{d}$ Cardiology and ${ }^{~}$ Clinical Biochemistry, \\ Haydarpasa Training Hospital, Gulhane Military Medical Academy, Kadıkoy-Istanbul, Turkey
}

\author{
Key Words \\ Methylmalonic acid - Acute myocardial infarction • \\ Vitamin $B_{12}$
}

\begin{abstract}
Objective: To investigate urinary methylmalonic acid ( $\mathrm{MMMA}$ ) levels and their relationship with markers of myocyte necrosis and inflammation in patients with acute myocardial infarction (AMI). Subjects and Methods: The study participants consisted of 80 consecutive patients with AMI and 72 age- and sex-matched consecutive controls. Of the patients, 38 had ST segment elevation myocardial infarction (STEMI) and 42 had non-ST segment elevation. All patients with STEMI underwent fibrinolytic therapy. Routine laboratory tests included troponin-I, creatinine phosphokinase $M B$ (CK-MB), high-sensitivity C-reactive protein (hs-CRP), vitamin $B_{12}$, folate, homocysteine and methylmalonic acid analyses. UMMA measurements were made by a spectrophotometric method. Results: uMMA levels were significantly higher in patients with AMl than in controls (10.1 vs. $5.2 \mathrm{mmol} / \mathrm{mol}$ creatinine, $\mathrm{p}<0.001$ ) and higher in patients with anterior $\mathrm{MI}$ compared to those with non-anterior MI (18.9 vs. $8.7 \mathrm{mmol} /$ mol creatinine, $p<0.001)$. In addition, uMMA levels were significantly higher in patients without successful reperfusion compared to those with successful reperfusion. In patients with STEMI, a strong positive association was found between urinary MMA and plasma hs-CRP levels $(r=0.81, p<0.001)$,
\end{abstract}

symptom duration $(r=0.91, p<0.001)$ and wall motion score $(r=0.60, p=0.006)$. More importantly, a strong positive association was observed between uMMA and the size of myocardial infarction in patients without successful reperfusion (for CK-MB $r=0.81, p=0.013$; for wall motion score $r=0.82$, $\mathrm{p}=0.012$ ). Conclusion: uMMA levels were elevated in patients with AMI and, as such, may be a candidate biochemical indicator of larger infarct size and enhanced inflammation in patients with AMI.

Copyright $\odot 2009$ S. Karger AG, Basel

\section{Introduction}

Methylmalonic acid (MMA) metabolism during acute myocardial infarction has not yet been thoroughly studied. Acute myocardial infarction (AMI) is likely to remain a major cause of death as the proportion of elderly people, who have a higher incidence of morbidity and mortality, increases [1]. Although methylmalonyl-CoA mutase enzyme activation has been observed during cerebral ischemia, there are limited data about urinary MMA (uMMA) levels and their clinical implications in AMI.

MMA in serum and urine is derived from the hydrolysis of D-methylmalonyl-CoA, which is a metabolic intermediate in the conversion of propionic acid to succinic acid [2]. The conversion of methylmalonyl-CoA to succinyl-CoA requires vitamin $\mathrm{B}_{12}$, so impaired cobalamin

\section{KARGER}

Fax +41613061234

E-Mail karger@karger.ch

www.karger.com
(C) 2009 S. Karger AG, Basel

1011-7571/09/0183-0217\$26.00/0

Accessible online at:

www.karger.com/mpp
Dr. Turgay Celik

Department of Cardiology, Gulhane School of Medicine

TR-06018 Etlik-Ankara (Turkey)

Tel. +90 3123044268 , Fax +90 3123044250

E-Mail benturgay@yahoo.com 
function causes an increased concentration of extracellular MMA [3], which thereby becomes a sensitive marker of cobalamin status [2]. Serum MMA, however, is not a specific marker of cobalamin status because its concentrations are also elevated in renal failure, thyroid disease, small-bowel bacterial overgrowth and conditions of hemoconcentration [4]. uMMA, however, is normalized to creatinine concentrations and, therefore, corrected for both dehydration and renal insufficiency. Moreover, the measurement of uMMA is not only noninvasive but also requires only a random urine specimen [4].

MMA may contribute to neuronal injury in many human conditions in which it accumulates, including methylmalonyl-CoA mutase and $\mathrm{B}_{12}$ deficiency $[5,6]$. Narasimhan et al. [7] demonstrated that methylmalonyl-CoA mutase is induced by several stresses, including ischemia, and this decreases the accumulation of MMA, an endogenous cellular mitochondrial inhibitor and neurotoxin.

MMA levels were found to be significantly higher in patients suffering from AMI, while the intake of vitamin $\mathrm{B}_{12}$ was not associated with the risk of myocardial infarction [8]. However, there are few studies about the clinical significance of MMA in patients with AMI. The aim of the present study was to assess uMMA levels in patients presenting with AMI, to compare these with controls, and to determine the relationship between uMMA and other markers of myocyte necrosis and inflammation.

\section{Subjects and Methods}

\section{Patients}

The study population consisted of 80 consecutive patients with AMI (38 females and 42 males, mean age \pm SD $64 \pm 8$ years) and 72 consecutive age- and sex-matched controls (32 females and 40 males, mean age \pm SD $61 \pm 8$ years) drawn from those patients seen at our institution in 2002 and 2003 who were eligible for the study. In the study group, 38 patients had ST segment elevation myocardial infarction (STEMI; 24 anterior, 14 non-anterior) and 42 patients had non-ST segment elevation myocardial infarction (NSTEMI). The diagnosis of AMI was established using the American College of Cardiology/European Society of Cardiology criteria [9].

Patients with known or proven cerebrovascular accidents, psychiatric disorders, delirium tremens, any chronic inflammatory-autoimmune disease, any neurologic disorders, renal impairment (serum creatinine $>176.4 \mu \mathrm{mol} / \mathrm{l}$ ), known malignancy, drug ingestion which might affect $B_{12}$ metabolism, intestinal malabsorption, exocrine pancreatic insufficiency, gastrectomy, or gastritis (especially antral gastritis) were excluded from the current study.

All patients were evaluated by standard physical examination, serial resting 12-lead ECG, routine laboratory tests including se- rum troponin-I, creatinine phosphokinase $\mathrm{MB}$ band (CK-MB), high-sensitivity C-reactive protein (hs-CRP), plasma vitamin $B_{12}$, folate, homocysteine and uMMA measurements. Of the patients with STEMI, 38 who had no contraindication to fibrinolytic treatment underwent fibrinolytic therapy. Clinical reperfusion criteria were used for assessing the efficacy of fibrinolytic treatment in patients with STEMI. Clinical reperfusion was defined as complete resolution of chest pain, run of accelerated idioventricular rhythm and a decrease of at least 70\% in ST segment elevation on surface ECG at 90 min after fibrinolytic therapy.

\section{Blood Sampling and Urine Collection}

Blood samples for the determination of cardiac enzymes (CK and CK-MB fraction, GPT and LDH) and markers (troponin-I) were collected at hospital admission and at 8-hour intervals, until 2 consecutive drops in CK-MB activity were obtained.

Blood samples for the measurement of vitamin $B_{12}$ and hsCRP were taken at hospital admission. Urine samples of patients with AMI were collected over $8 \mathrm{~h}$ by means of transurethral catheters upon admission; urine from the control group was collected in the morning.

\section{Urine MMA Measurement Method}

The uMMA measurements were made based on a modified photometric method [10] that utilized a scanning spectrophotometer (UV/VIS scanning spectrophotometer, PU 8700 series, Philips, UK). This method is based on the reaction between methylmalonic acid and diazotizated $p$-nitroaniline.

\section{Other Laboratory Analyses}

Serum vitamin $\mathrm{B}_{12}$, folate, CK-MB and troponin-I measurements were made using automated immunoassays using the Abbott IMx analyzer (Abbott Laboratories, Chicago, Ill., USA). Plasma total homocysteine levels were determined by high performance liquid chromatography with fluorescence detection using a commercial assay (Chromosystems, Munich, Germany). Serum hs-CRP measurements were made using the nephelometric method and Beckman Array nephelometry.

\section{Echocardiography}

Transthoracic echocardiography was performed using the VingMed System Five echocardiographic system (GE Medical Systems, Horten, Norway) at the left lateral decubitis position after fibrinolytic treatment. Left ventricular ejection fraction was calculated using Simpson's rule. Wall motion of 16 myocardial segments was interpreted according to the criteria of the American Society of Echocardiography [11]. The wall thickening of each myocardial segment was scored as follows: normokinesia or hyperkinesia $=0$; hypokinesia $=1$; severe hypokinesia $=2$; akinesia $=3$; dyskinesia $=4$. The wall motion score was calculated as the sum of the scores within the area at risk.

\section{Statistical Analysis}

Results are expressed as the mean $\pm \mathrm{SD}$, median (minimum to maximum) and percentages. Kolmogorov-Smirnov and Levene tests were used to determine the distribution characteristics of variables and variance homogenity. With respect to these test results, we used independent sample $t$ tests or Mann-Whitney $U$ tests as appropriate. Differences between control and patient groups were tested for significance by $\chi^{2}$ test, Fisher's exact test, 
Table 1. Baseline characteristics of the patients and controls

\begin{tabular}{lccc}
\hline & $\begin{array}{l}\text { Myocardial in- } \\
\text { farction }(\mathrm{n}=80)\end{array}$ & $\begin{array}{l}\text { Control } \\
(\mathrm{n}=72)\end{array}$ & $\mathrm{p}$ \\
\hline Age, years & $64 \pm 8$ & $61 \pm 8$ & $0.15^{\mathrm{a}}$ \\
Male & $42(52 \%)$ & $40(55 \%)$ & $0.79^{\mathrm{b}}$ \\
Body mass index & $30.7 \pm 2.6$ & $27.8 \pm 3.0$ & $0.09^{\mathrm{a}}$ \\
Hypertension & $40(50 \%)$ & $8(11 \%)$ & $0.02^{\mathrm{b}}$ \\
Diabetes mellitus & $33(41 \%)$ & $9(12 \%)$ & $0.01^{\mathrm{b}}$ \\
Family history & $22(27 \%)$ & $6(8 \%)$ & $0.01^{\mathrm{b}}$ \\
Smoking & $46(57 \%)$ & $30(41 \%)$ & $0.44^{\mathrm{b}}$ \\
\hline
\end{tabular}

Values are mean $\pm \mathrm{SD}$.

${ }^{a}$ Independent samples t test. ${ }^{\mathrm{b}} \chi^{2}$ test.

independent sample $t$ test and Mann-Whitney $U$ test. The relationship between variables was analyzed with Pearson's correlation test. Differences and correlations were considered significant at $\mathrm{p}<0.05$. Statistical analyses were performed using SPSS 11.5 Statistical Package program for Windows (SPSS Inc., Chicago, Ill., USA).

\section{Results}

Comparison of baseline clinical characteristics of patients with AMI and those of controls showed that several classical risk factors were found to be significantly higher in patients with AMI than controls $(\mathrm{p}<0.05)$ but not smoking, age, gender or BMI (table 1). Analysis of biochemical parameters showed that troponin-I, plasma peak CK-MB, hs-CRP and uMMA levels were significantly higher in patients with AMI than the controls (table 2). More importantly, uMMA levels were higher in patients with AMI than in controls [median (min.-max.) $10.1(3.1-29.3)$ vs. $5.2(2.6-7.9) \mathrm{mmol} / \mathrm{mol}$ creatinine, $\mathrm{p}<$ $0.001]$.

A moderately positive association was found between plasma hs-CRP $(\mathrm{r}=0.56, \mathrm{p}<0.001)$, peak plasma CK-MB $(\mathrm{r}=0.47, \mathrm{p}=0.019)$ and troponin-I levels $(\mathrm{r}=0.54, \mathrm{p}<$ 0.001 ) and uMMA levels in patients with AMI (fig. 1). A good positive correlation was found between uMMA and wall motion score $(\mathrm{r}=0.65, \mathrm{p}<0.001)$ and symptom duration $(r=0.90, p<0.001)$. There was also a negative association between uMMA and left ventricular ejection fraction (LVEF; $r=-0.61, p<0.001$ ) in patients with AMI.

Analysis of the patients with STEMI showed a strong positive association between uMMA and plasma hs-CRP

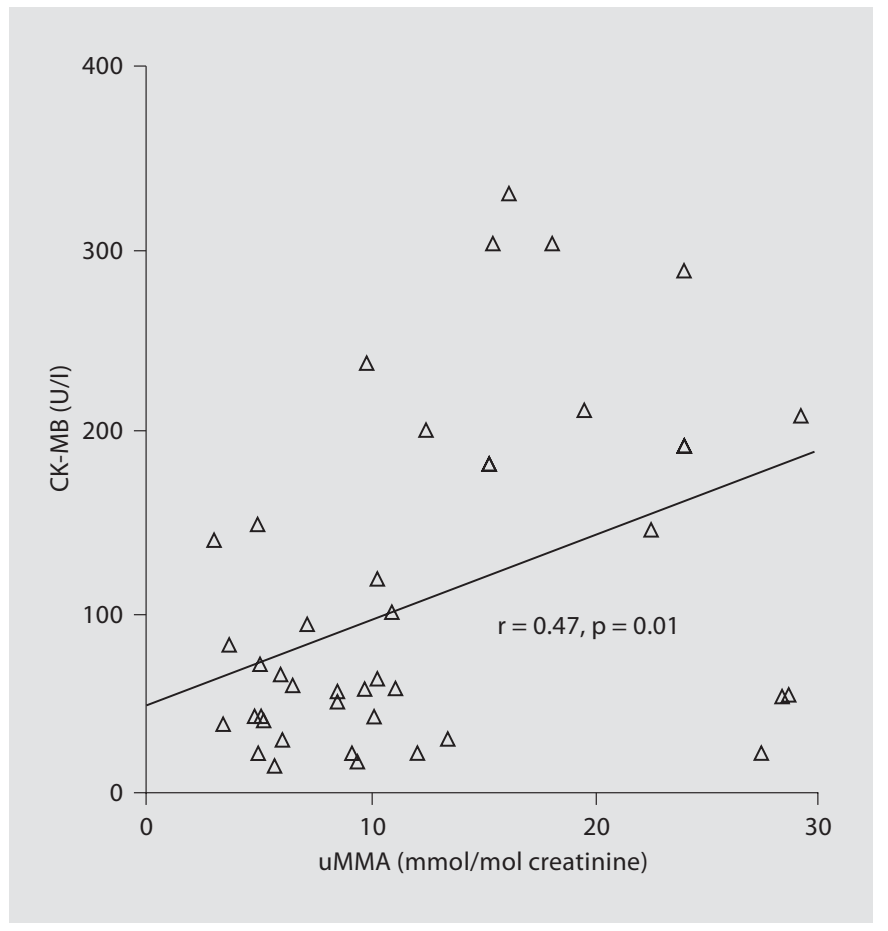

Fig. 1. The correlation between uMMA and CK-MB isoenzyme levels in patients with acute myocardial infarction.

levels $(\mathrm{r}=0.81, \mathrm{p}<0.001)$, symptom duration $(\mathrm{r}=0.91$, $\mathrm{p}<0.001)$ and wall motion score $(\mathrm{r}=0.60, \mathrm{p}=0.006)$. Also, a strong negative correlation was found between uMMA levels and LVEF ( $r=-0.75, p<0.001)$. uMMA levels in patients with STEMI were found to be higher compared to those of the patients with NSTEMI [table 3; median (min.-max.) 15.3 (3.7-29.3) vs. 6.1 (3.1-28.5) $\mathrm{mmol} / \mathrm{mol}$ creatinine, $\mathrm{p}=0.002]$.

Complete clinical reperfusion was achieved in 24 patients after fibrinolytic treatment. Strong positive associations were observed between uMMA levels, CK-MB $(\mathrm{r}=0.81, \mathrm{p}=0.013)$ and wall motion score $(\mathrm{r}=0.82 \mathrm{p}=$ 0.012 ) in patients without successful clinical reperfusion. Besides, a strong positive correlation was detected between uMMA levels and symptom duration in patients with clinical reperfusion $(\mathrm{r}=0.91, \mathrm{p}<0.001)$. Also, $\mathrm{uMMA}$ levels were significantly lower in patients with clinical reperfusion compared to those patients without clinical reperfusion [table 4: median (min.-max.) 9.9 (3.7-29.3) vs. $21.1(15.5-28.7) \mathrm{mmol} / \mathrm{mol}$ creatinine, $\mathrm{p}=0.002)]$.

Examination of uMMA levels in patients with STEMI based on infarction location demonstrated that uMMA levels were higher in patients with anterior myocardial infarction compared to those with non-anterior myocar- 
Table 2. Comparison of various biochemical parameters between the patient and control groups

\begin{tabular}{lccr}
\hline & $\begin{array}{l}\text { Myocardial } \\
\text { infarction }(\mathrm{n}=80)\end{array}$ & $\begin{array}{l}\text { Control } \\
(\mathrm{n}=72)\end{array}$ & $\mathrm{p}$ \\
\hline uMMA, mmol/mol creatinine & $10.1(3.1-29.3)$ & $5.2(2.6-7.9)$ & $<0.001$ \\
Homocysteine, $\mu \mathrm{mol} / \mathrm{l}$ & $10.1 \pm 1.3$ & $9.7 \pm 1.1$ & 0.121 \\
Vitamin $\mathrm{B}_{12}, \mathrm{pg} / \mathrm{ml}$ & $298.8 \pm 65.1$ & $302.1 \pm 65.1$ & 0.832 \\
Folate, $\mathrm{ng} / \mathrm{ml}$ & $9.5 \pm 0.9$ & $9.2 \pm 0.8$ & 0.150 \\
hs-CRP, $\mu \mathrm{g} / \mathrm{dl}$ & $12.0(2.0-45.0)$ & $3.0(1.0-11.0)$ & $<0.001$ \\
Total cholesterol, mg/dl & $226.8 \pm 36.3$ & $220.0 \pm 44.1$ & 0.520 \\
Triglyceride, mg/dl & $220.0 \pm 44.1$ & $218.2 \pm 39.8$ & 0.850 \\
HDL cholesterol, mg/dl & $39.0 \pm 7.8$ & $38.7 \pm 5.1$ & 0.843 \\
Peak CK-MB, U/l & $60.0(13.6-329.0)$ & $13.0(5.0-28.0)$ & $<0.001$ \\
Troponin-I, ng/ml & $8.4(0.2-26.7)$ & $0(0-0.1)$ & $<0.001$ \\
\hline
\end{tabular}

Values are given as mean \pm SD or median (min.-max.).
Table 3. The comparison of biochemical parameters between the patients with STEMI and NSTEMI

\begin{tabular}{lccr}
\hline & STEMI $(\mathrm{n}=38)$ & NSTEMI $(\mathrm{n}=42)$ & \multicolumn{1}{c}{$\mathrm{p}$} \\
\hline Age, years & $62 \pm 8$ & $66 \pm 6$ & 0.090 \\
uMMA, mmol/mol creatinine & $15.3(3.7-29.3)$ & $6.1(3.1-28.5)$ & 0.002 \\
Vitamin $\mathrm{B}_{12}, \mathrm{pg} / \mathrm{ml}$ & $310.9 \pm 65.2$ & $288.0 \pm 65.5$ & 0.272 \\
Homocysteine, $\mu \mathrm{mol} / \mathrm{l}$ & $10.0 \pm 1.0$ & $10.3 \pm 1.5$ & 0.434 \\
Folate, $\mathrm{ng} / \mathrm{ml}$ & $9.4 \pm 0.9$ & $9.6 \pm 0.9$ & 0.545 \\
hs-CRP, $\mu \mathrm{g} / \mathrm{dl}$ & $18.0(2.5-45.0)$ & $10.0(2.0-25.0)$ & 0.015 \\
Peak CK-MB, U/l & $180.0(48.9-329.0)$ & $40.0(13.6-147.0)$ & $<0.001$ \\
Troponin-I, ng/ml & $16.3(0.8-26.7)$ & $6.0(0.2-17.1)$ & 0.001 \\
LVEF, \% & $46.4 \pm 8.6$ & $48.6 \pm 8.5$ & 0.100 \\
Wall motion score & $14.9 \pm 4.0$ & $13.1 \pm 3.7$ & 0.151 \\
\hline
\end{tabular}

Values are given as mean \pm SD or median (min.-max.). dial infarction, as presented in table 5 [median (min.max.) 18.9 (9.9-29.3) vs. $8.7(3.7-11.2) \mathrm{mmol} / \mathrm{mol}$ creatinine, $\mathrm{p}<0.001]$. Moreover, moderate-to-good positive correlations were observed between uMMA levels and plasma hs-CRP $(r=0.66)$, troponin levels $(r=0.64)$ and occlusion time $(r=0.71)$ in patients with anterior AMI $(\mathrm{p}<0.05$ for all).

\section{Discussion}

The current study reveals that uMMA levels were elevated in patients with AMI compared to those of controls. Moreover, uMMA levels were found to be higher in patients without clinical reperfusion than patients in whom clinical reperfusion was achieved.

The conversion of methylmalonyl-CoA to succinylCoA requires vitamin $B_{12}$, therefore a deficiency of vita- min $B_{12}$ increases the concentration of MMA [12]. Although vitamin $B_{12}$ showed no clear association with AMI, the levels of MMA were reported to be higher in patients with AMI [7]. In fact, uMMA concentrations often increase in the early stages of vitamin $B_{12}$ deficiency before measurable decreases in serum vitamin $B_{12}$ are evident at the tissue level [13]. In the current study, serum vitamin $\mathrm{B}_{12}$ levels of patients with AMI were not different from those of the controls. However, uMMA levels were significantly higher in patients with AMI compared with those of controls. Therefore, it may be a plausible to suggest that one of the mechanisms resulting in the increase of MMA in patients with AMI might be $\mathrm{B}_{12}$ deficiency at a myocardial tissue level during myocardial ischemia. On the other hand, deficiency of vitamin $\mathrm{B}_{12}$ and folate are frequently seen in elderly individuals [14-17], with estimated prevalences of 5-40\%. Increased MMA and homocysteine have been observed in elderly people in spite 
Table 4. A comparison of biochemical parameters relating to clinical reperfusion

\begin{tabular}{lccc}
\hline & $\begin{array}{l}\text { Clinical } \\
\text { reperfusion }(\mathrm{n}=22)\end{array}$ & $\begin{array}{l}\text { No clinical } \\
\text { reperfusion }(\mathrm{n}=16)\end{array}$ & $\mathrm{p}$ \\
\hline Age, years & $62 \pm 3$ & $65 \pm 5$ & 0.112 \\
uMMA, mmol/mol creatinine & $9.9(3.7-29.3)$ & $21.1(15.5-28.7)$ & 0.002 \\
Vitamin $\mathrm{B}_{12}, \mathrm{pg} / \mathrm{ml}$ & $313.8 \pm 69.7$ & $306.9 \pm 63.0$ & 0.831 \\
Homocysteine, $\mu \mathrm{mol} / \mathrm{l}$ & $9.7 \pm 1.0$ & $10.3 \pm 1.1$ & 0.250 \\
Folate, $\mathrm{ng} / \mathrm{ml}$ & $9.3 \pm 1.0$ & $9.5 \pm 0.9$ & 0.72 \\
hs-CRP, $\mu \mathrm{g} / \mathrm{dl}$ & $11.5(2.5-27.0)$ & $30.5(18.0-45.0)$ & 0.001 \\
Peak CK-MB, U/l & $81.0(48.9-235.0)$ & $248.0(53.3-329.0)$ & 0.033 \\
Troponin-I, ng/ml & $9.3(0.8-25.4)$ & $20.2(16.3-26.7)$ & 0.012 \\
LVEF, \% & $52.3 \pm 6.1$ & $40.6 \pm 6.8$ & $<0.001$ \\
Wall motion score & $12.9 \pm 3.3$ & $17.6 \pm 3.2$ & 0.006 \\
Symptom duration, h & $3.5(2.0-6.8)$ & $7.8(6.0-9.0)$ & $<0.001$ \\
\hline
\end{tabular}

Values are given as mean $\pm \mathrm{SD}$ or median (min.-max.).
Table 5. A comparison of biochemical parameters in patients with STEMI according to the location of myocardial infarction

\begin{tabular}{lccr}
\hline & Anterior $(\mathrm{n}=24)$ & Nonanterior $(\mathrm{n}=14)$ & \multicolumn{1}{c}{$\mathrm{p}$} \\
\hline Age, years & $65 \pm 6$ & $63 \pm 7$ & 0.140 \\
uMMA, mmol/mol creatinine & $18.9(9.9-29.3)$ & $8.7(3.7-11.2)$ & $<0.001$ \\
Vitamin $\mathrm{B}_{12}, \mathrm{pg} / \mathrm{ml}$ & $296.4 \pm 55.8$ & $335.7 \pm 76.9$ & 0.210 \\
Homocysteine, $\mu \mathrm{mol} / \mathrm{l}$ & $10.1 \pm 1.1$ & $9.8 \pm 1.1$ & 0.530 \\
Folate, $\mathrm{ng} / \mathrm{ml}$ & $9.3 \pm 0.9$ & $9.6 \pm 1.1$ & 0.472 \\
hs-CRP, $\mu \mathrm{g} / \mathrm{dl}$ & $24.9(11.5-45.0)$ & $9.0(2.5-18.0)$ & $<0.001$ \\
Peak CK-MB, U/l & $208.5(53.3-329.0)$ & $57.0(48.9-92.0)$ & 0.001 \\
Troponin-I, ng/ml & $18.9(9.3-26.7)$ & $5.6(0.8-24.1)$ & 0.010 \\
LVEF, \% & $42.9 \pm 7.2$ & $55.0 \pm 4.1$ & 0.001 \\
Wall motion score & $16.9 \pm 3.3$ & $11.4 \pm 2.1$ & 0.001 \\
Symptom duration, h & $6.9(3.0-9.0)$ & $3.5(2.0-4.0)$ & $<0.001$ \\
\hline
\end{tabular}

Values are given as mean $\pm \mathrm{SD}$ or median (min.-max.). of serum concentrations of the $B$ vitamins, including $B_{12}$, being within the appropriate reference intervals $[14,15]$. Therefore, functional vitamin $\mathrm{B}_{12}$ deficiency may be encountered in the elderly, especially in the very old (age $>80$ years). So, it is probable that functional $B_{12}$ deficiency in our study population might have increased their uMMA levels. However, our study population and control patients were of similar age, and all were in the 'young-old' age range.

Plasma homocysteine levels were not different in patients with AMI compared to controls. It is known that the concentrations of homocysteine in serum and plasma are elevated in both folate and vitamin $B_{12}$ deficiencies, whereas MMA in serum, plasma or urine is a specific marker of vitamin $B_{12}$ function [3]. From that point of view, it is possible that deficiency of vitamin $B_{12}$ at tissue level during myocardial ischemia may result in increased uMMA.

The increased uMMA levels in patients with STEMI in whom complete clinical reperfusion was not achieved led us to consider that ongoing myocardial ischemia may be associated with increased uMMA. Increased uMMA levels may, therefore, be a new complementary marker of unsuccessful reperfusion treatment. Contrary to brain ischemia, methylmalonyl-CoA mutase enzyme activity in the heart may be inhibited during myocardial ischemia, although that needs experimental evidence.

In the present study, a strong positive correlation was found between uMMA and hs-CRP in patients with AMI. It was previously reported that an elevated serum hs-CRP level was related to a worse clinical outcome, including pump failure, atrial fibrillation and left ventricu- 
lar aneurysmal formation during AMI [18-20]. Also, CRP is not only a marker of the amount and activity of circulating proinflammatory cytokines, it may also contribute to inflammation in ischemic myocardium by activating the complement system [21]. Although the data obtained from the current study imply that increased uMMA concentrations in AMI may be a secondary phenomenon to enhanced hs-CRP, there has been no report to date indicating whether enhanced inflammation causes an increase of uMMA. The presence of a strong relationship between uMMA levels and symptom duration time led us to conclude that increased uMMA levels may be one of the time-dependent markers of ongoing myocardial necrosis. From that standpoint, it is possible that admission uMMA might be another new marker of ongoing myocardial necrosis and inflammation in the area supplied by the infarct-related artery in patients with AMI. We also found an association between uMMA levels and markers of infarction size such as peak CK-MB,
troponin-I concentrations, wall motion score and LVEF in patients with AMI. These findings suggest that uMMA levels may also be related to infarct size.

The design and size of the present study do not allow us to draw a conclusion on a temporal relationship between an AMI event and MMA excretion in urine. Assay of methylmalonyl-CoA mutase enzyme activity in the study groups and monitoring of uMMA in patients with AMI some time after infarction would also have been helpful in that regard.

\section{Conclusion}

uMMA levels are increased in patients with AMI. uMMA warrants further investigation as a potential biochemical indicator of larger infarct size, enhanced inflammation and of incomplete reperfusion in these patients.

\section{References}

1 American Heart Association: Heart and Stroke Statistical Update. Dallas, AHA, 2008.

$\checkmark 2$ Allen RH, Stabler SP, Savage DG, Lindenbaum J: Metabolic abnormalities in cobalamin (vitamin B12) and folate deficiency. FASEB J 1993; 7:1344-1353.

>3 Barness LA, Young D, Mellman WJ, Kahn SB, Williams WJ: Methylmalonate excretion in a patient with pernicious anemia. $\mathrm{N}$ Engl J Med 1963;268:144-146.

4 Bjorke Monsen AL, Ueland PM: Homocysteine and methylmalonic acid in diagnosis and risk assessment from infancy to adolescence. Am J Clin Nutr 2003;78:7-21.

5 Behrens MI, Koh J, Canzoniero LM, Sensi SL, Csernansky CA, Choi DW: 3-Nitropropionic acid induces apoptosis in cultured striatal and cortical neurons. Neuroreport 1995; 6:545-548

6 Zeevalk GD, Derr-Yellin E, Nicklas WJ: Relative vulnerability of dopamine and GABA neurons in mesencephalic culture to inhibition of succinate dehydrogenase by malonate and 3-nitropropionic acid and protection by NMDA receptor blockade. J Pharmacol Exp Ther 1995;275:1124-1130.

7 Narasimhan P, Sklar R, Murrell M, Swanson RA, Sharp FR: Methylmalonyl-CoA mutase induction by cerebral ischemia and neurotoxicity of the mitochondrial toxin methylmalonic acid. J Neurosci 1996;16:73367346.

$>8$ Verhoef P, Stampfer MJ, Buring JE, Gaziano JM, Allen RH, Stabler SP, Reynolds RD, Kok FJ, Hennekens CH, Willett WC: Homocysteine metabolism and risk of myocardial in- farction: relation with vitamins B6, B12, and folate. Am J Epidemiol 1996;143:845-859.

$\checkmark 9$ Alpert JS, Thygesen K, Antman E, Bassand JP: Myocardial infarction redefined: a consensus document of the Joint European Society of Cardiology/American College of Cardiology Committee for the redefinition of myocardial infarction. J Am Coll Cardiol 2000;36:959-969.

10 Gultepe M, Ozcan O, Avsar K, Cetin M, Ozdemir AS, Gok M: Urine methylmalonic acid measurements for the assessment of cobalamin deficiency related to neuropsychiatric disorders. Clin Biochem 2003;36:275-282.

-11 Schiller NB, Shah PM, Crawford M, DeMaria A, Devereux R, Feigenbaum H, Gutgesell H, Reichek N, Sahn D, Schnittger I: Recommendations for quantitation of the left ventricle by two-dimensional echocardiography. American Society of Echocardiography Committee on Standards, Subcommittee on Quantitation of Two-Dimensional Echocardiograms. J Am Soc Echocardiogr 1989;2:358-367.

12 Savage DG, Lindenbaum J, Stabler SP, Allen $\mathrm{RH}$ : Sensitivity of serum methylmalonic acid and total homocysteine determinations for diagnosing cobalamin and folate deficiencies. Am J Med 1994;96:239-246.

13 Klee GG: Cobalamin and folate evaluation: measurement of methylmalonic acid and homocysteine vs. vitamin $\mathrm{B}(12)$ and folate. Clin Chem 2000;46:1277-1283.

14 Herrmann W, Schorr H, Bodis M, Knapp JP, Muller A, Stein G, Geisel J: Role of homocysteine, cystathionine and methylmalonic acid measurement for diagnosis of vitamin defi- ciency in high-aged subjects. Eur J Clin Invest 2000;30:1083-1089.

15 Lindenbaum J, Rosenberg IH, Wilson PW, Stabler SP, Allen RH: Prevalence of cobalamin deficiency in the Framingham elderly population. Am J Clin Nutr 1994;60:2-11.

16 Morris MS, Jacques PF, Rosenberg IH, Selhub J: Elevated serum methylmalonic acid concentrations are common among elderly Americans. J Nutr 2002;132:2799-2803.

17 Obeid R, Schorr H, Eckert R, Herrmann W: Vitamin $B_{12}$ status in the elderly as judged by available biochemical markers. Clin Chem 2004;50:238-241.

-18 Casl MT, Surina B, Glojnaric-Spasic I, Pape E, Jagarinec N, Kranjcevic S: Serum amyloid A protein in patients with acute myocardial infarction. Ann Clin Biochem 1995;32:196200.

19 Pietila K, Harmoinen A, Teppo AM: Acute phase reaction, infarct size and in-hospital morbidity in myocardial infarction patients treated with streptokinase or recombinant tissue type plasminogen activator. Ann Med 1991;23:529-535.

20 Takahashi T, Anzai T, Yoshikawa T, Maekawa Y, Asakura Y, Satoh T, Mitamura H, Ogawa S: Serum C-reactive protein elevation in left ventricular remodeling after acute myocardial infarction: role of neurohormones and cytokines. Int J Cardiol 2003;88:257-265.

21 Lagrand WK, Niessen HW, Wolbink GJ, Jaspars LH, Visser CA, Verheugt FW, Meijer CJ, Hack CE: C-reactive protein colocalizes with complement in human hearts during acute myocardial infarction. Circulation 1997;95: 97-103. 